\title{
Antibacterial Coatings on Titanium Surfaces: A Comparison Study Between In Vitro Single-Species and Multispecies Biofilm
}

\author{
Maria Godoy-Gallardo ${ }^{a \dagger \$ s}$,Zhejun Wang ${ }^{\# \&}$, Ya Shen ${ }^{\#}$, José M. Manero ${ }^{\dagger \neq \$}$,Francisco J. \\ Gil $^{\dagger \neq}$,Daniel Rodriguez ${ }^{* \dagger \$}$, Markus Haapasalo ${ }^{\#}$. \\ ${ }^{\dagger}$ Biomaterials, Biomechanics and Tissue Engineering Group, Department of Materials Science and Metallurgy, \\ Technical University of Catalonia (UPC), ETSEIB, Av. Diagonal 647, 08028-Barcelona, Spain. \\ ${ }^{\ddagger}$ CIBER de Bioingeniería, Biomateriales y Nanomedicina (CIBER-BBN), Campus Río Ebro, Edificio I+D Bloque \\ 5, $1^{\mathrm{a}}$ planta, C/ Poeta Mariano Esquillor s/n, 50018-Zaragoza, Spain. \\ ${ }^{\S}$ Centre for Research in NanoEngineering (CRNE) - UPC, C/ Pascual i Vila 15, 08028-Barcelona, Spain \\ ${ }^{\#}$ Division of Endodontics, Department of Oral Biological and Medical Sciences, University of British Columbia, \\ Vancouver, Canada, V6T 1 Z3 \\ ${ }^{\&}$ The State Key Laboratory Breeding Base of Basic Science of Stomatology (Hubei-MOST) \& Key Laboratory of \\ Oral Biomedicine Ministry of Education, School \& Hospital of Stomatology, Wuhan University, 237 Luoyu Road, \\ Wuhan, PR China.
}

KEYWORDS: single biofilm; multispecies biofilm; antibacterial coatings; titanium; hLf1-11 immobilization; silver electrodeposition; TESPSA silanization

\begin{abstract}
Dental plaque is a biofilm that causes dental caries, gingivitis and periodontitis. Most of the studies in antibacterial coatings have been conducted by in vitro single-species biofilm formation but oral biofilm involves more than 700 different bacterial species that are able to interact. Therefore, new studies are focused on in vitro multispecies biofilm model that mimic in vivo biofilms. The aim of the present work was to study different antibacterial coatings onto titanium surfaces, and evaluate the in vitro antimicrobial properties of the surfaces on two different bacterial species and an oral biofilm. Lactate dehydrogenase assay determined that treated samples did not affect fibroblast viability. In addition, the viability of microorganisms on modified samples was evaluated by LIVE/DEAD BacLight bacterial viability kit. Although a decrease in viable bacteria onto treated samples was obtained, the results showed differences in effectiveness when single-biofilm and oral plaque were tested. It confirms, as we expected, the distinct sensitivities that bacterial strains have. Thus, this multispecies biofilms model holds a great potential to assess antibacterial properties onto samples for dental purposes.
\end{abstract}




\section{Introduction}

Peri-implantitis is a disease which appears when dental plaque induces inflammation of the periimplant tissue and it is associated with bone loss ${ }^{1,2}$. Implant plaque consists of an oral biofilm initiated by free-floating bacterial cells attaching to the implant surface. Then, the microorganisms grow into mature, structurally complex biofilm where some bacteria detach into the oral environment.

Most of the studies in antibacterial implant coatings have been conducted by in vitro singlespecies biofilm formation, although oral biofilm involves more than 700 different interacting bacterial species ${ }^{3-5}$. The bacterial complexity of dental plaque is divided into two groups regarding their effect in biofilm formation: primary and late colonizers. Primary colonizers consist mainly of Streptococcus genus (such as Streptococcus sanguinis) and display higher adherence capabilities compared to other bacterial species ${ }^{6,7}$. Other primary colonizers are Actinomyces, Veillonella and Haemophilus genera. ${ }^{8-10}$ The late colonizers include bacteria such as Prevotella intermedia, Treponema denticola, Aggregatibacter actinomycetemcomitans, Tannerella forsythia and Porphyromonas gingivalis. ${ }^{8-10}$ In particular, Lactobacillus salivarius interacts with other colonizers and their metabolic products are necessary for the biofilm formation and maintenance. ${ }^{11}$ Therefore, the development of new in vitro multispecies biofilm models should seek to better mimic the characteristics of in vivo biofilms.

Based on these premises, a new in vitro multispecies biofilm model has been proposed ${ }^{12-14}$ in order to evaluate the efficacy of antibacterial conditions. For that purpose, confocal laser scanning microscopy (CLSM) has been considered as the most useful technique for threedimensional reconstruction, identification of viable bacteria and to compare biofilm modifications under different agents.

Titanium is the material of choice for dental implants because of its mechanical properties and the capability of osseointegration. However, several challenges must be overcome to provide titanium devices with antibacterial properties. One strategy to prevent infections is the deposition of antibacterial agents on titanium surfaces. Specifically, silver has been shown to be effective as a broad-spectrum antibacterial material, even against drug-resistant strains. ${ }^{15,16}$ Different techniques have been used to incorporate silver onto the surface of biomaterials such as electrodeposition, ${ }^{17}$ chemical vapor deposition ${ }^{18}$ and magnetron co-sputtering ${ }^{19}$. Other methods are based in the titanium surface modification by using self-assembled monolayers (SAMs) which could serve as a initiator for further biomolecules immobilization. ${ }^{20-22}$ The type of biomolecule depends on the appropriate terminal functional group in the monolayer, e.g. alkanethiols, disulphides, trichlorosilanes, trimethoxysilanes, organosilicon hydrides, phosphoric acids and phosphates ${ }^{23}$. In the case of silanization, a silane can create a covalent bond with the hydroxyl groups present on metal surfaces (e.g. titanium) and fix the hydroxylsilane onto the substrate $^{24}$. Moreover, they are able to covalently immobilize biomolecules (e.g. an antimicrobial peptides) promoting specific cells responses ${ }^{25}$. Antimicrobial peptides (AMP) have recently 
attracted much attention due to their strong antibacterial activity against a broad spectrum of microorganisms and low rates of bacterial resistance ${ }^{20,26-29}$. Their activity is due to their capacity to target and disrupt bacterial membranes. ${ }^{26,30,31}$ Although AMPs vary in sequence and structure, all of them adopt an amphipathic structure which interact with phospholipids of the bacteria membrane and increase its permeability, which is destructive for the bacteria ${ }^{26,32}$. An example is the peptide hLf1-11, the 1-11 amino acid segment sequence of human lactoferrin, which is able

to destabilize the plasma membrane of the bacteria by depolarization and iron-binding ${ }^{33,34}$.

Alternatively, biomaterial surfaces may be functionalized by grafting of polymer brushes by atom transfer radical polymerization (ATRP). Polymer brushes consist of an assembly of polymer chains which are in contact with the surface substrate by one terminal end. Moreover, ATRP enhances the efficiency of peptide immobilization due to an increase in the spatial density of diverse number of functional groups on the surface.

This work has two main goals: (1) to investigate the efficiency of five antibacterial coatings on titanium (silver electrodeposition, TESPSA silane coating, hLf1-11 peptide binding with 3chloropropyl triethoxysilane (CPTES) silane and ATRP peptide binding with two different chemical routes); (2) to compare the antibacterial properties of these coatings on single species and multispecies oral biofilms.

\section{Materials and Methods}

\subsection{Sample preparation}

Titanium (c.p grade 2) disks (10mm diameter, $2 \mathrm{~mm}$ thickness) were smoothed up to a surface roughness $\left(\mathrm{R}_{\mathrm{a}}\right)$ under $40 \mathrm{~nm}$. Once polished, samples were cleaned with isopropanol, ethanol, water and acetone for 15 min each by sonication.

\subsection{Surface treatment procedures}

\subsubsection{Silver electrodeposition}

The silver electrodeposition process was controlled with a Potentiostat (PARSTAT 2273, Princeton Applied Research, Oak Ridge, TN, USA) and applied as previously explained ${ }^{17}$. Briefly, a potential with a rectangular pulse shape $(\mathrm{EI}=0 \mathrm{~V}, \mathrm{EF}=5 \mathrm{~V}, \mathrm{ST}=500 \mathrm{~ms}, \mathrm{SH}=10$ $\mathrm{mV}, \mathrm{PW}=100 \mathrm{~ms}$ ) was applied to the working electrode, with a full-cycle period of $25 \mathrm{~s}$. The electrolyte consisted in $0.1 \mathrm{M}$ of $\mathrm{AgNO}_{3}$ and $0.2 \mathrm{M}$ of $\mathrm{Na}_{2} \mathrm{~S}_{2} \mathrm{O}_{3}$, whereas the time of each process was 500 cycles. The new surface was performed on the abutment, remaining the implant untreated. After treatment, all samples were sonicated in ethanol, distilled water, and acetone for 15 min each. 


\subsubsection{TESPSA silanization}

Titanium surfaces were activated with $5 \mathrm{M} \mathrm{NaOH}$ for $24 \mathrm{~h}$ at $60{ }^{\circ} \mathrm{C}$. ${ }^{35}$ Subsequently, samples were cleaned by immersion in distilled water for $30 \mathrm{~min}$ twice, washed with acetone and dried with nitrogen gas. Pretreated titanium samples were silanized with TESPSA $(0.5 \%, \mathrm{v} / \mathrm{v})$ in anhydrous toluene for $1 \mathrm{~h}$ at $70{ }^{\circ} \mathrm{C}$ in nitrogen atmosphere. The silanization was applied in dissolution of $3 \%(\mathrm{v} / \mathrm{v})$ of N,N-diisopropylethylamine (DIEA) to maintain a basic environment. Once the reaction was completed, samples were sonicated with distilled water for 10 minutes, washed with isopropanol, ethanol, distilled water and acetone, and dried with nitrogen.

\subsubsection{Immobilization of hLf1-11 peptide onto titanium samples by CPTES silanization}

The immobilization of the hLf1-11 peptide on titanium surfaces has been previously described by Godoy-Gallardo et $a l^{20}$ as an adaptation from other protocols. ${ }^{28,36,37}$ Briefly, surfaces were activated by alkaline etching and then silanized with CPTES $(2.0 \%, \mathrm{v} / \mathrm{v})$ in anhydrous toluene. Then, a crosslinker (maleimide acid $\mathrm{N}$-hydroxysuccinimide ester) was added to the silanized surfaces and finally the hLf1-11 peptide was immobilized by overnight immersion $(200 \mu \mathrm{M}$ solution of hLf1-11 dissolved in $0.5 \mathrm{mg} / \mathrm{mL}$ of $\mathrm{Na}_{2} \mathrm{CO}_{3}$ ). Surfaces were washed with PBS and dried with nitrogen.

\subsubsection{Immobilization of hLf1-11 peptide onto titanium samples by atom transfer radical polymerization (ATRP)}

This process corresponds to protocols published by Gao et $a l^{38,39}$ and Godoy-Gallardo et al. ${ }^{40}$ Concisely, titanium surfaces were activated with oxygen plasma treatment (Standard Plasma System Femto, Diener electronic GmbH, Germany) at a power of $100 \mathrm{~W}$ for $10 \mathrm{~min}$. A first group of samples (Ti_ACoI_Lf) were silanized with 3-Triethoxysilylpropylamine (APTES) and the amino group was activated prior to the ATRP process. ${ }^{40}$ A second group of samples (Ti_BCoI_Lf) were immersed overnight in a solution of 11-(2-bromo-2-methyl) propionyloxyundecenyltrichlorosilane (BPTCS) in toluene at room temperature (the synthesis of BPTCS was detailed by Matyjaszewski et $a l^{41}$ ). Samples were cleaned and dried with nitrogen.

Afterwards, ATRP was performed for all samples by the copolymerization of DMA-APMA followed by overnight incubation in a solution of hLf1-11 $(1 \mathrm{mg} / \mathrm{ml})$ in PBS $(\mathrm{pH} 8.5)$ at room temperature. Remaining activated groups were capped by immersion in 2-mercaptoethanol for $24 \mathrm{~h}$ and samples were sonicated with PBS and dried with nitrogen. 


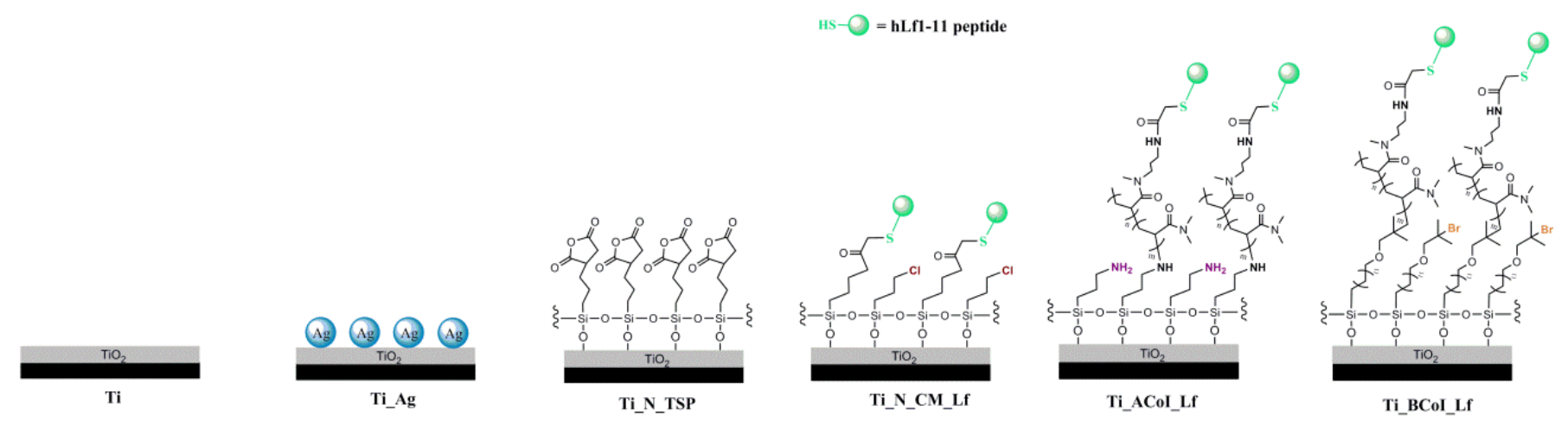

Figure 1. Schematic representation of the applied surface treatments.

The treated samples (Figure 1) and their controls were codified as follows:

- Ti: Smooth titanium

- Ti_Ag: Titanium + silver electrodeposition

- Ti_N_TSP: Titanium + TESPSA

- Ti_N_CM_Lf: Titanium + CPTES + maleimide crosslinker + hLf1-11 peptide

- Ti_ACoI_Lf: Titanium + APTES + DMA-APMA copolymer + iodoacetyl crosslinker + hLf1-11 peptide

- Ti_BCoI_Lf: Titanium + BPTCS + DMA-APMA copolymer + iodoacetyl crosslinker + hLf1-11 peptide

\subsection{Physicochemical characterization of the surfaces}

\subsubsection{Morphological analysis}

Scanning electron microscopy (Zeiss Neon40 FE-SEM, Carl Zeiss NTS GmbH, Germany) was used to observe the surface morphology of the samples. Five images were taken for each surface at a working distance of $7 \mathrm{~mm}$ and a potential of $5 \mathrm{kV}$.

\subsubsection{Contact angle analysis}

Static water contact angles were measured with distilled water (Millipore Milli-Q, Merck Millipore Corporation, USA) using the sessile drop method (Contact Angle System OCA15 plus; Dataphysics, Germany). Measurements were acquired in triplicate for three samples in each series at room temperature, with a volume of $3 \mu 1$ and a dose rate of $1 \mu 1 / \mathrm{min}$.

Surface energy was also calculated with the Owens, Wendt, Rabel and Kaelble (OWRK) equation applied to both water and diiodomethane measurements, as previously explained. ${ }^{20,40}$ Data was interpreted with SCA 20 software (Dataphysics).

\subsubsection{Roughness analysis}

White light interferometry (Wyko NT1100, Veeco Instruments, USA) was used to measure the surface topography of the samples by a $5 \times$ objective lens and an area of $736 \times 480 \mu \mathrm{m}$. Three 
measurements were collected at different positions on three samples of each group. The arithmetic average height $\left(\mathrm{R}_{\mathrm{a}}\right)$, the surface skewness $\left(\mathrm{R}_{\mathrm{sk}}\right)$ and the surface kurtosis $\left(\mathrm{R}_{\mathrm{ku}}\right)$ were studied. $^{42,43}$ Data analysis was performed with Wyko Vision $232^{\mathrm{TM}}$ software (Veeco Instruments).

\subsubsection{X-ray photoelectron spectroscopy analysis}

The chemical composition of the surfaces was analyzed by X-ray photoelectron spectroscopy (XPS). Measurements were performed using an XR50 Mg anode source operating at $150 \mathrm{~W}$ and a Phoibos 150 MCD-9 detector (D8 advance, SPECS Surface Nano Analysis GmbH, Germany).

High resolution spectra were collected using $25 \mathrm{eV}$ at $0.1 \mathrm{eV}$ steps with a chamber pressure below $7.5 \cdot 10^{-9}$ mbar. Binding energies were calibrated using the $\mathrm{C} 1 \mathrm{~s}$ signal at $480 \mathrm{eV}$. Two specimens were analyzed for each studied condition.

\subsection{Biological characterization of the surfaces}

\subsubsection{Cell culture of human foreskin fibroblasts (HFFs)}

Details of the cell culture assays were described previously elsewhere. ${ }^{17,20,40}$ HFFs cells were grown and maintained in supplemented DMEM. Cells were cultured in $75 \mathrm{~cm}^{2}$ cell culture flasks at $37^{\circ} \mathrm{C}$ and the medium was refreshed every 2 days. HFFs were detached by trypsinization, centrifuged for $5 \mathrm{~min}$ at $300 \mathrm{~g}$, re-suspended in fresh DMEM medium and seeded. Cells between passage three and eight were used in all experiments.

\subsubsection{Cell cytotoxicity assay}

Indirect in vitro cytotoxicity tests of the treated surfaces HFFs cells were carried out analyzing the activity of the lactate dehydrogenase (LDH) enzyme by Cytotoxicity Detection Kit LDH. Each specimen was immersed in DMEM for $72 \mathrm{~h}$ at $37 \pm 2^{\circ} \mathrm{C}$ with an extraction medium are/volume ratio of $0.5 \mathrm{~cm}^{2} / 1 \mathrm{ml}$ (according to ISO 10993-5). Afterwards, the extraction medium was removed and diluted with DMEM (dilution $1 / 0 ; 1 / 1 ; 1 / 10 ; 1 / 100$ and 1/1000). ${ }^{40}$

HFFs were seeded at 5000 cells $/ \mathrm{ml}$ in a 96-well plate and allowed to adhere for $24 \mathrm{~h}$ at $37^{\circ} \mathrm{C}$. Then, the media was aspired, substituted by the extracts and incubated for another $24 \mathrm{~h}$. The release of LDH was determined by measuring the optical density of $490 \mathrm{~nm}$ by an ELx800 Universal Microplate Reader (Bio-Tek Instruments, Inc. Winooski, VT, USA).

\subsubsection{Cell proliferation assay}

Additionally, the cell proliferation rate was assessed by Cytotoxicity Detection Kit LDH assay. A quantity of 5000 cells was seeded on modified surfaces placed in 48 -well plates and evaluated at $4 \mathrm{~h}, 24 \mathrm{~h}, 72 \mathrm{~h}$ and $168 \mathrm{~h}$ of incubation with complete medium. Afterwards, cells were lysed 
with $200 \mu \mathrm{l} /$ well of ${\mathrm{M}-\mathrm{PER}^{\circledR}}^{\circledR}$ and the release of LDH was measured, as explained in cell cytotoxicity assay.

\subsubsection{Antimicrobial properties of the treated surfaces}

The bacterial assays were carried out by following protocols reported in the literature to evaluate the efficiency of antibacterial coatings. ${ }^{20,40}$ The strains used in the study were Streptococcus sanguinis (CECT 480, Colección Española de Cultivos Tipo (CECT), Valencia, Spain) and Lactobacillus salivarius (CCUG 17826, Culture Collection University of Göteborg (CCUG), Göteborg, Sweden). Moreover, the oral plaque collected from one volunteer was also used. The Human research ethics committee of the University of British Columbia (permission H12-02430) approved this experiment. S. sanguinis was grown and maintained on Todd-Hewitt (TH) broth (Scharlau Todd-Hewitt broth, Scharlab SL, Sentmenat, Spain), L. salivarius on MRS broth (Scharlau MRS broth, Scharlab SL) and oral plaque on Heart Infusion Broth (BHI) (Difco, Detroit, MI, USA). For mono-species biofilm, the bacteria suspensions were incubated overnight at $37^{\circ} \mathrm{C}$ in air before each assay and the optical density was adjusted to $0.2 \pm 0.01$ at $600 \mathrm{~nm}$ (about $1 \cdot 10^{8}$ colony forming units $(\mathrm{CFU}) / \mathrm{ml}$ ). For the oral plaque, the optical density was adjusted to 0.1 at $405 \mathrm{~nm}$ and then diluted 1:10. ${ }^{12,13}$ All assays were performed in static conditions and three replicates for each condition were used.

\subsubsection{Bacterial adhesion on titanium surfaces}

As described by Godoy-Gallardo et al, ${ }^{20,40}$ modified samples were incubated with $1 \mathrm{ml}$ of the proper bacterial suspension solution for $2 \mathrm{~h}$ at $37^{\circ} \mathrm{C}$. Afterwards, the suspension was aspired and disks were rinsed twice with PBS. Then, bacteria were detached from the titanium surface by vortexing in $1 \mathrm{ml}$ of PBS for 5 min. ${ }^{17,20,40}$ These bacteria were diluted and seeded on TH agar for S.sanguinis, MRS agar plates for L.salivarius and Tryptic Soy Agar for oral plaque. CFU plate counting was performed after $24 \mathrm{~h}$ of incubation at $37^{\circ} \mathrm{C}$ and expressed as adhered CFU/ $/ \mathrm{cm}^{2}$.

\subsubsection{Viability of bacteria on modified samples}

Measure of bacteria viability was adapted from protocols previously reported by GodoyGallardo $^{40}$ and Shen et al. ${ }^{12-14}$ Biofilm formation was assessed with the LIVE/DEAD BacLight bacterial viability kit (Life Technologies, Carlsbad, CA, USA). $1 \mathrm{ml}$ of bacterial suspension $\left(1 \cdot 10^{8}\right.$ cells $/ \mathrm{ml}$, ABS $0.2 \pm 0.01$ at $\left.600 \mathrm{~nm}\right)$ was seeded onto titanium surfaces and incubated at $37^{\circ} \mathrm{C}$ for $1,2,3$ and 4 weeks in anaerobic conditions. After incubation, samples were washed twice with PBS and transferred into a 48-well microtiter plate (Nunc, Thermo Scientific, Waltham, MA, USA). Adherent bacteria were stained by incubation with $50 \mu \mathrm{l}$ of a dye-solution $\left(1.5 \mu \mathrm{l}\right.$ of $\mathrm{SYTO}^{\circledR}$ and $1.5 \mu \mathrm{l}$ propidium iodide $/ 1 \mathrm{ml} \mathrm{NaCl}$ buffer $(0.85 \%)$ ) for $15 \mathrm{~min}$. Dyed surfaces were analyzed by confocal laser scanning microscopy CLSM images with a $20 \times 1$ lens. Images were acquired with the software EZ-C1 (EZ-C1 v3.40, build 691, Nikon, NY, USA) at five random positions of the surfaces and a stack of 40 slices ( $1 \mu \mathrm{m}$ thick each) were scanned. 
Image stacks were analyzed by Imaris software (Bitplane, Zurich, Switzerland) in order to evaluate the volume ratio of dead cells.

\subsection{Statistical analysis}

All data were analyzed by a non-parametric U Mann-Whitney test (IBM SPSS Statistics 20 software, Armonk, NY, USA). Statistical significance was set at a $\mathrm{P}$ value $<0.05$.

\section{RESULTS}

\subsection{Morphological analysis}
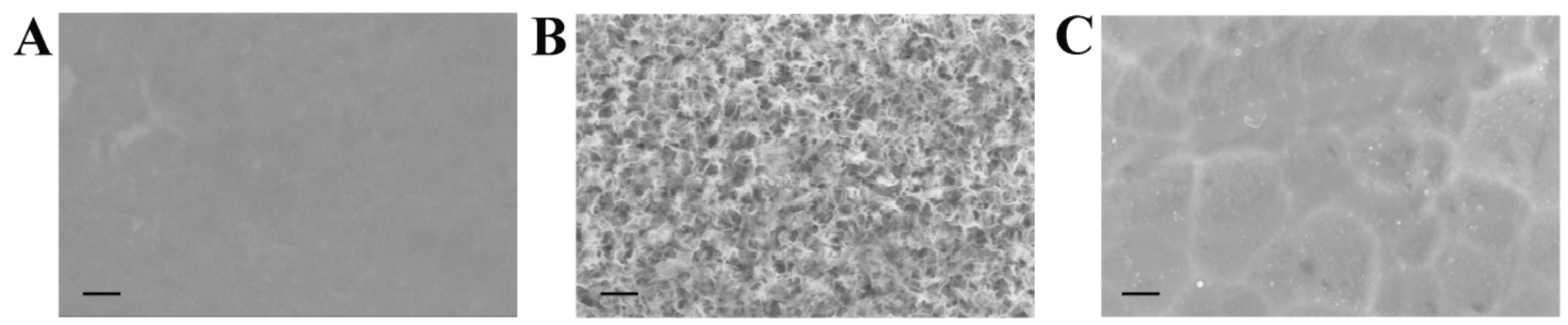

Figure 2. SEM images of (A) smooth titanium (Ti) and samples activated by plasma (Ti_ACoI_Lf and Ti_BCoI_Lf); (B) titanium activated with $\mathrm{NaOH}$ pre-treatment (Ti_N_TSP and T_N_CM_Lf); (C) Silver electrodeposited (Ti_Ag) (Scale: $300 \mathrm{~nm}$ ).

As shown in Figure 2(A), plasma activation, subsequent brush polymerization and finally hLf111 conjugation (Ti_ACoI_Lf and Ti_BCoI_Lf) did not alter the morphology of the sample in comparison with control titanium (Ti). However, sodium hydroxide treatment resulted in noticeable differences in morphology (Ti_N_TSP and Ti_N_CM_Lf, Figure 2(B)). NaOH treated samples revealed a layer of micropore-structure ${ }^{35}$ (less than $1 \mu \mathrm{m}$ in diameter) of sodium titanate. ${ }^{44}$ Likewise, silver electrodeposition treatment exposed round etchings and globular deposits which a homogeneously distribution onto the titanium surfaces. These deposits, even after intense sonication, remained on the surface.

\subsection{Contact angle analysis}

In order to establish the surface hydrophobicity at a microscopic scale, contact angle and surface energy were evaluated (Table 1). TESPSA and lactoferrin peptide immobilization by silanization (Ti_N_TSP and Ti_N_CM_Lf) onto surfaces decrease contact angle values with a significant increment of the SFE. In contrast, silver deposition and covalent immobilization of hLf1-11 on polymerized substrates (Ti_ACoI_Lf and Ti_BCoI_Lf) increased CA values in comparison with its control (data not shown). An increase in the polar component of the SFE of these samples was 
also observed. The modifications of the SFE were mostly due to changes in its polar component since dispersive part remained fairly constant.

Table 1. Values (mean \pm standard deviation) of contact angle (CA), surface free energy (SFE), with dispersive (DISP) and polar (POL) components, for each surface treatment. Statistically significant differences versus control Ti are indicated with a ' $*$ ' $(\mathrm{P}<0.05)$.

\begin{tabular}{|c|c|c|c|c|}
\hline & $\mathrm{CA}\left({ }^{\circ}\right)$ & $\operatorname{SFE}\left(\mathrm{m} J / \mathrm{m}^{2}\right)$ & $\operatorname{DISP}\left(\mathrm{m} J / \mathrm{m}^{2}\right)$ & $\operatorname{POL}\left(\mathrm{mJ} / \mathrm{m}^{2}\right)$ \\
\hline $\begin{array}{l}\text { Ti } \\
\text { Ti Ag }\end{array}$ & $\begin{array}{c}68.7 \pm 2.7 \\
64.1 \pm 2.9^{*}\end{array}$ & $\begin{array}{c}47.5 \pm 2.4 \\
51.9 \pm 2.3^{*}\end{array}$ & $\begin{array}{l}39.4 \pm 2.2 \\
42.5 \pm 2.4\end{array}$ & $\begin{array}{l}8.1 \pm 1.2 \\
9.4 \pm 1.5\end{array}$ \\
\hline Ti_N_TSP & $31.2 \pm 4.6^{*}$ & $71.8 \pm 2.1 *$ & $47.3 \pm 1.1^{*}$ & $24.5 \pm 2.2^{*}$ \\
\hline Ti_N_CM_Lf & $51.6 \pm 9.9^{*}$ & $60.2 \pm 5.4^{*}$ & $45.2 \pm 1.5^{*}$ & $15.0 \pm 5.2^{*}$ \\
\hline Ti_ACoI_Lf & $64.6 \pm 2.7 *$ & $47.0 \pm 1.8$ & $35.5 \pm 1.3^{*}$ & $11.5 \pm 1.5^{*}$ \\
\hline Ti_BCoI_Lf & $72.1 \pm 5.0^{*}$ & $46.3 \pm 2.3$ & $37.4 \pm 6.6$ & $6.6 \pm 2.6^{*}$ \\
\hline
\end{tabular}

Comparing rates of peptide attachment, the surface wettability was higher when the modification was carried on by polymerization than via silanization.

\subsection{Roughness analysis}

Table 2. Roughness values (mean \pm standard deviation) for each surface treatment. Statistically significant differences versus control Ti are indicated with an $*(\mathrm{P}<0.05)$.

\begin{tabular}{lccc} 
& $\mathbf{R}_{\mathbf{a}}[\mathbf{n m}]$ & $\mathbf{R}_{\mathbf{k u}}[\mathbf{n m}]$ & $\mathbf{R}_{\mathrm{sk}}[\mathbf{n m}]$ \\
\hline Ti & $25.1 \pm 5.4$ & $4.1 \pm 1.8$ & $0.8 \pm 0.6$ \\
Ti_Ag & $76 \pm 7 *$ & $11.0 \pm$ & $1.0 \pm 0.8$ \\
Ti_N_TSP & $96.9 \pm 6.2^{*}$ & $7.5 \pm 2.6$ & $0.4 \pm 0.8$ \\
Ti_N_CM_Lf & $95.0 \pm 30$. & $4.0 \pm 1.1$ & $2.6 \pm 1.1^{*}$ \\
Ti_ACoI_Lf & $30.5 \pm 3.1$ & $6.1 \pm 2.0$ & $1.9 \pm 1.0^{*}$ \\
Ti_BCoI_Lf & $30.4 \pm 3.5$ & $7.1 \pm 1.7$ & $2.0 \pm 1.3^{*}$ \\
\hline
\end{tabular}

The roughness was represented by three different parameters $\left(\mathrm{R}_{\mathrm{a}}, \mathrm{R}_{\mathrm{ku}}\right.$ and $\left.\mathrm{R}_{\mathrm{sk}}\right)$ (Table 2$)$. Pretreated samples with $\mathrm{NaOH}$ etching (Ti_N_TSP and Ti_N_CM_Lf) showed a statistically significant increase in roughness in comparison with control sample (Ti). Similarly, silver electrodeposition influenced the roughness of the Ti surfaces. In contrast, atom transfer radical polymerization treatment did not result in significant differences in surface roughness.

Both $\mathrm{R}_{\mathrm{ku}}$ and $\mathrm{R}_{\mathrm{sk}}$ parameters displayed higher values in almost all conditions in comparison with control titanium. 


\subsection{Chemical composition by X-ray photoelectron spectroscopy}

Table 3. Chemical composition (at \%) and $\mathrm{Si} / \mathrm{Ti}, \mathrm{S} / \mathrm{Ti}$ and $\mathrm{Ag} / \mathrm{Ti}$ relative atomic ratios.

\begin{tabular}{|c|c|c|c|c|c|c|c|c|c|c|}
\hline & C $15 \%$ & N 1 s \% & O 1s \% & S 2p \% & Si 2p \% & Ti 2p \% & Ag 3d & S/Ti & $\mathrm{Si} / \mathrm{Ti}$ & Ag/Ti \\
\hline $\mathbf{T i}$ & $36.3 \pm 7.3$ & $2.3 \pm 1.6$ & $47.9 \pm 6.4$ & $0.2 \pm 0.1$ & $1.1 \pm 0.7$ & $13.2 \pm 3.3$ & $*$ & $0.01 \pm 0.01$ & $0.1 \pm 0.8$ & \\
\hline Ti_Ag & $46.0 \pm 9.7$ & $1.0 \pm 0.4$ & $42.9 \pm 5.3$ & $1.5 \pm 0.6$ & $*$ & $5.8 \pm 4.2$ & $2.8 \pm 0.9$ & $*$ & & $0.6 \pm 0.3$ \\
\hline Ti_N_TSP & $41.2 \pm 9.0$ & $0.7 \pm 0.2$ & $42.7 \pm 6.5$ & $*$ & $6.9 \pm 1.6$ & $8.4 \pm 4.1$ & $*$ & $*$ & $1.0 \pm 0.5$ & $*$ \\
\hline Ti_N_CM_Lf & $57.4 \pm 2.5$ & $11.5 \pm 2.4$ & $26.0 \pm 1.5$ & $0.9 \pm 0.2$ & $1.6 \pm 0.4$ & $2.6 \pm 1.0$ & $*$ & $0.4^{\mathrm{a}} \pm 0.06$ & $0.6 \pm 0.07$ & $*$ \\
\hline Ti_ACoI_Lf & $58.6 \pm 1.7$ & $13.1 \pm 6.8$ & $23.9 \pm 7.4$ & $1.3 \pm 0.4$ & $1.0 \pm 0.1$ & $1.6 \pm 0.8$ & $*$ & $1.3^{\mathrm{b}} \pm 0.4$ & $0.7 \pm 0.3$ & $*$ \\
\hline Ti_BCoI_Lf & $71.8 \pm 1.0$ & $12.1 \pm 1.5$ & $13.7 \pm 0.1$ & $0.9 \pm 0.02$ & $0.7 \pm 0.1$ & $0.8 \pm 0.1$ & $*$ & $1.1^{\mathrm{c}} \pm 0.2$ & $0.8 \pm 0.04$ & $*$ \\
\hline
\end{tabular}

The atomic composition of all surfaces was studied by means of XPS (Table 3). For all the conditions, an increase in the percentage of $\mathrm{C} 1 \mathrm{~s}$ and $\mathrm{N} 1 \mathrm{~s}$ was observed. A reduction in $\mathrm{Ti} 2 \mathrm{p}$ signal in comparison with control titanium was measured in all samples, but a decrease in the $\mathrm{O}$ 1s signal was detected only in samples treated with either CPTES or ATRP method.

Silver electrodeposition was easily characterized by the presence of silver on the substrate $(2.8 \%$ for $\left.\mathrm{Ti} \_\mathrm{Ag}\right)$ and silanization by the presence of silicon $(6.9 \%$ for $\mathrm{Ti}$ _N_TSP, $1.6 \%$ for Ti_N_CM_Lf, $1.0 \%$ for Ti_ACoI_Lf and $1.7 \%$ for Ti_BCoI_Lf). Sulfur was also detected on electrodeposited surfaces (1.5\% for Ti_Ag) as well as on peptide-conjugated surfaces $(0.9 \%$ for Ti_N_CM_Lf, 1.3\% for Ti_ACoI_Lf and 0.9\% for Ti_BCoI_Lf).

The S/Ti ratio indicated that ATRP facilitated peptide attachment compared to silanization (S/Ti ratio of 0.4 for Ti_AI_Lf, 1.3 for Ti_ACoI_L, and 1.1 for Ti_BCoI_Lf).

\subsection{Cell cytotoxicity assay}

Comparisons between the 6 test groups at 1 day incubation for different concentrations of cell culture extract are summarized in Figure 3. After $24 \mathrm{~h}$, the viability of cells exposed to treated samples was not significantly different compared to control titanium (Ti). Thus, all modified samples had low or non-cytotoxic effect.

\subsection{Cell proliferation assay}

For all test groups, the proliferation of HFFs over $4 \mathrm{~h}, 1,3$ and 7 days of incubation were measured (Figure 4). For $4 \mathrm{~h}$ and $1 \mathrm{~d}$ of culture, samples covered by ATRP strategy showed a lower number of viable cells than untreated titanium. However, no significant differences in cell proliferation were observed between treated samples and control ones. 


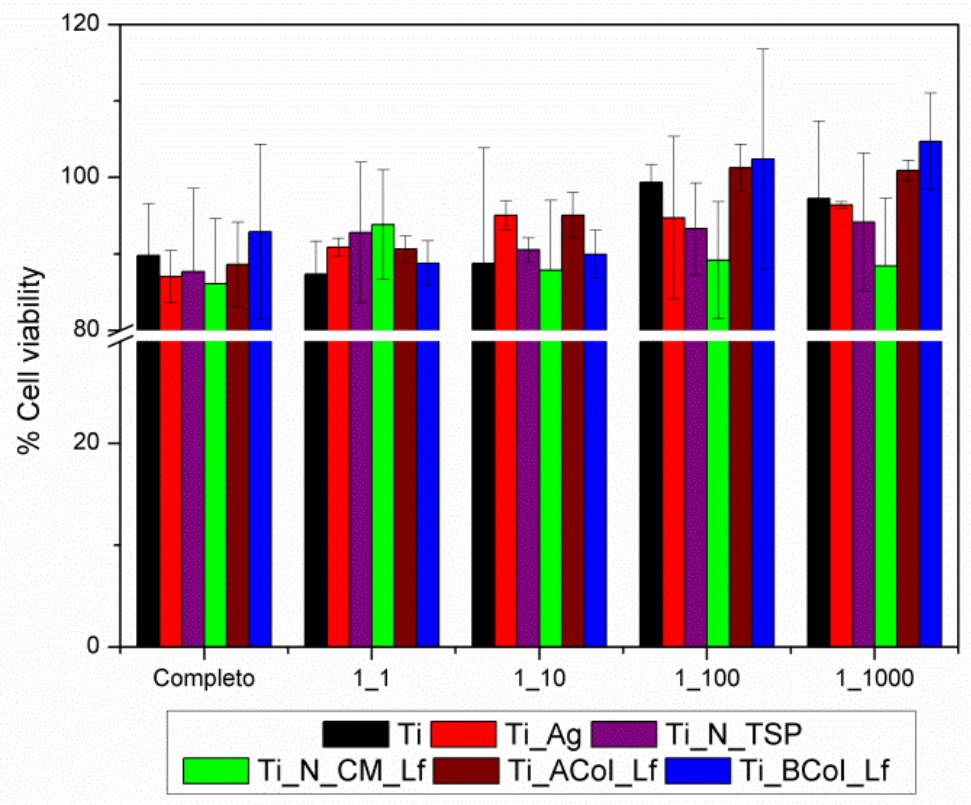

Figure 3. Cytotoxicity of HFFs on titanium surfaces after 1-day incubation. Asterisk (*) indicates statistically significant differences with Ti.

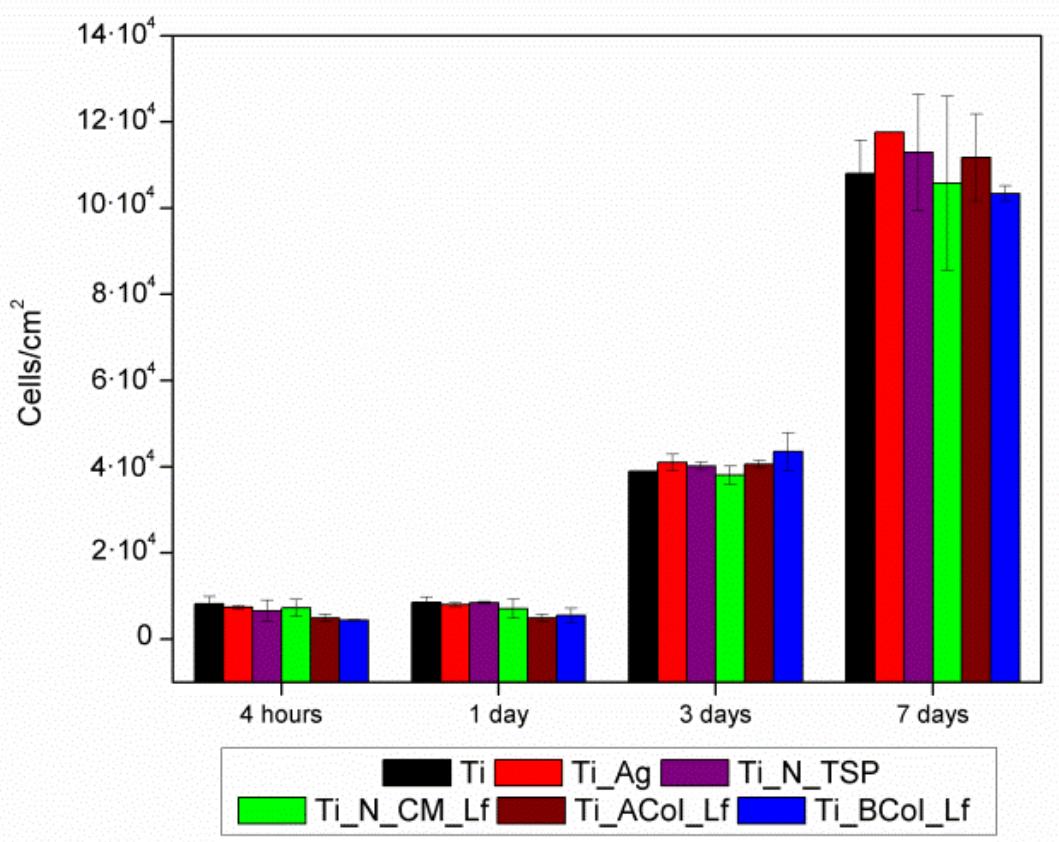

Figure 4 Proliferation of HFFs on the studied surfaces after 4 h, 24 h, $72 \mathrm{~h}$ and $168 \mathrm{~h}$ of incubation measured by an LDH assay. Asterisk $(*)$ indicates statistically significant differences with the control group. 


\subsection{Bacterial adhesion on titanium surfaces assay}

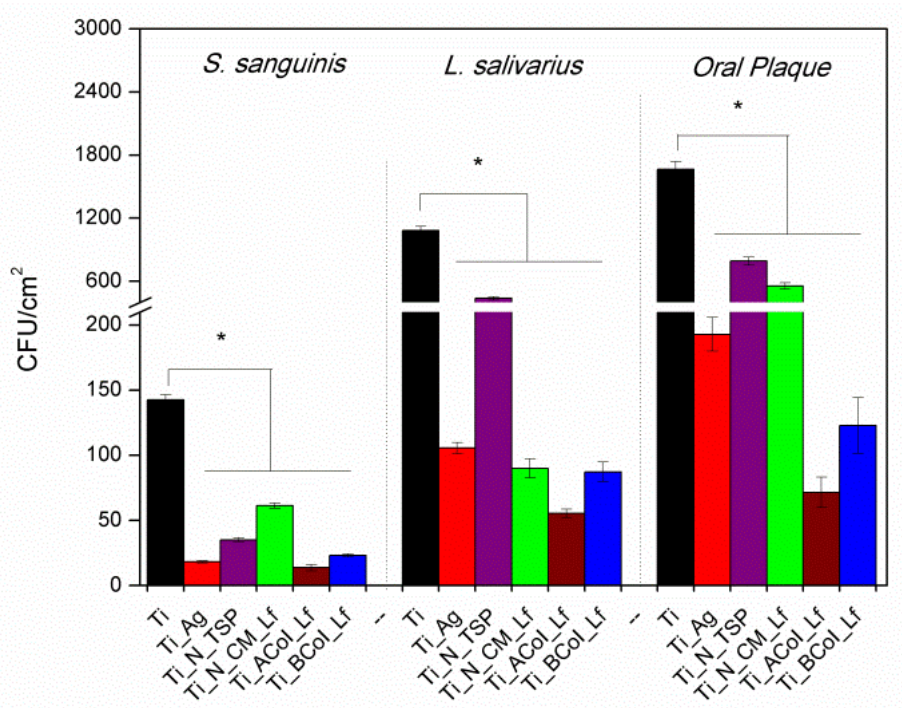

Figure 5. Bacterial adhesion of oral plaque, S. sanguinis and L. salivarius on titanium surfaces after $2 \mathrm{~h}$ of incubation at $37^{\circ} \mathrm{C}$. Statistically significant differences are indicated with an “*” $(\mathrm{P}<0.05)$.

Results of bacteria assay for S.sanguinis, L.salivarius and Oral plaque after $2 \mathrm{~h}$ of incubation on treated samples and control titanium are shown in Figure 5. All modified samples significantly reduced the adhesion of all bacteria suspensions, with the highest reduction measured for S.sanguinis. Moreover, the samples with hLf1-11 peptide attached by ATRP polymerization (Ti_ACoI_Lf and Ti_BCoI_Lf) showed the highest reduction.

\subsection{Viability of microorganisms on modified samples}

Results of live bacteria on modified surfaces and control titanium after 1,2, 3 and 4 weeks of incubation are shown in Figure 6. Overall, all treated surfaces drastically reduced the number of viable bacteria of both strains and the oral plaque. Control titanium surfaces showed no statistically significant differences on bacteria viability at different times for all three conditions. In particular, silver electrodeposited exhibited the highest antibacterial effect onto titanium surfaces (Ti_Ag). Noteworthy, single-species biofilm (S.sanguinis and L.salivarius) displayed a higher decrease in comparison with oral multispecies biofilm (oral plaque).

Interestingly, an increase of the presence of live bacteria in treated samples was detected after the fourth week for all conditions, except for Ti_N_TSP and Ti_Ag samples with L.salivarius cultures. 

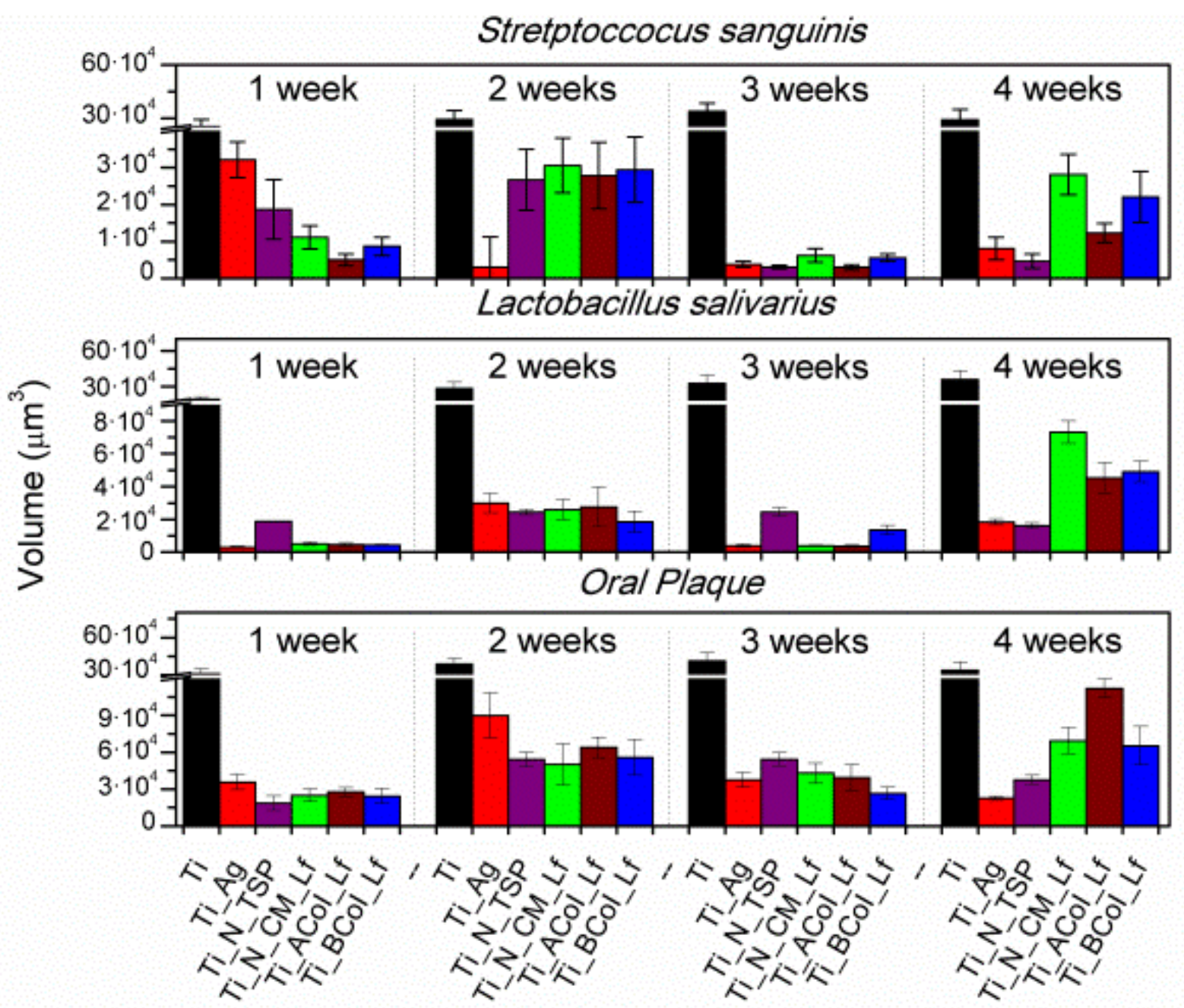

Figure 6. Live bacteria S. sanguinis, L. salivarius and oral plaque at different times of incubation at $37^{\circ} \mathrm{C}$.

The ratio of death/live bacteria was measured (Table 4) to confirm the antibacterial properties of the treated surfaces. All treated samples exhibited a higher death/live ratio than control titanium through all times of study. Moreover, during the first two weeks no differences were detected among the three different biofilms. However, after 3 weeks, the death/live ratio was lower when multi-species biofilm was used instead of a single strain biofilm. 
Table 4. Ratio of death bacteria [red cells/(red cells + green cells)] for 1 and 2 weeks of incubation at $37^{\circ} \mathrm{C}$.

\begin{tabular}{l|ccc|ccc}
\cline { 2 - 7 } & \multicolumn{3}{|c|}{ 1 week } & \multicolumn{3}{c}{ 2 weeks } \\
\cline { 2 - 7 } & S.sanguinis & L.salivarius & Oral & S.sanguinis & L.salivarius & Oral \\
\hline Ti & $0.001 \pm 0.0$ & $0.003 \pm$ & $0.001 \pm 0.0$ & 0.002 & $0.04 \pm 0.04$ & $0.002 \pm$ \\
Ti_Ag & $0.1 \pm 0.05$ & $0.06 \pm 0.04$ & $0.1 \pm 0.06$ & $0.4 \pm 0.2$ & $0.3 \pm 0.2$ & $0.2 \pm 0.1$ \\
Ti_N_TSP & $0.1 \pm 0.07$ & $0.1 \pm 0.08$ & $0.1 \pm 0.08$ & $0.1 \pm 0.05$ & $0.2 \pm 0.08$ & $0.3 \pm 0.06$ \\
Ti_N_CM_Lf & $0.1 \pm 0.05$ & $0.1 \pm 0.06$ & $0.1 \pm 0.06$ & $0.4 \pm 0.2$ & $0.4 \pm 0.2$ & $0.2 \pm 0.09$ \\
Ti_ACoI_Lf & $0.1 \pm 0.05$ & $0.4 \pm 0.2$ & $0.1 \pm 0.06$ & $0.6 \pm 0.3$ & $0.4 \pm 0.2$ & $0.3 \pm 0.2$ \\
Ti_BCoI_Lf & $0.1 \pm 0.04$ & $0.3 \pm 0.1$ & $0.1 \pm 0.07$ & $0.4 \pm 0.09$ & $0.2 \pm 0.07$ & $0.4 \pm 0.07$ \\
\cline { 2 - 7 } & \multicolumn{3}{|c|}{ 3 week } & & & 4 week \\
\cline { 2 - 7 } & S.sanguinis & L.salivarius & Oral & S.sanguinis & L.salivarius & Oral \\
\hline Ti & $0.04 \pm 0.04$ & $0.004 \pm$ & $0.02 \pm 0.04$ & $0.05 \pm 0.05$ & $0.03 \pm 0.04$ & $0.03 \pm 0.03$ \\
Ti_Ag & $0.5 \pm 0.05$ & $0.5 \pm 0.08$ & $0.3 \pm 0.1$ & $0.3 \pm 0.08$ & $0.3 \pm 0.2$ & $0.5 \pm 0.1$ \\
Ti_N_TSP & $0.1 \pm 0.06$ & $0.5 \pm 0.1$ & $0.4 \pm 0.1$ & $0.3 \pm 0.07$ & $0.4 \pm 0.2$ & $0.5 \pm 0.1$ \\
Ti_N_CM_Lf & $0.4 \pm 0.08$ & $0.4 \pm 0.2$ & $0.4 \pm 0.2$ & $0.3 \pm 0.08$ & $0.6 \pm 0.2$ & $0.3 \pm 0.1$ \\
Ti_ACoI_Lf & $0.4 \pm 0.1$ & $0.5 \pm 0.1$ & $0.5 \pm 0.1$ & $0.6 \pm 0.2$ & $0.5 \pm 0.2$ & $0.2 \pm 0.1$ \\
Ti_BCoI_Lf & $0.3 \pm 0.1$ & $0.5 \pm 0.2$ & $0.4 \pm 0.2$ & $0.6 \pm 0.2$ & $0.6 \pm 0.2$ & $0.3 \pm 0.1$ \\
\hline
\end{tabular}

Streptococcus sanguinis
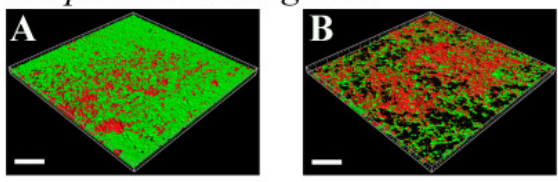

Lactobacillus salivarius
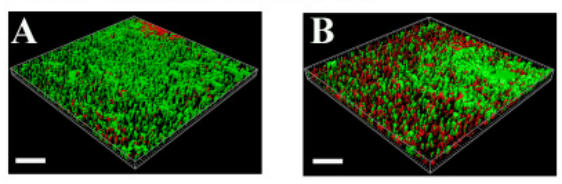

Oral Plaque
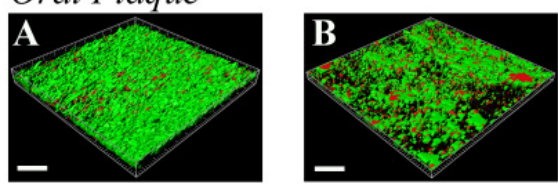
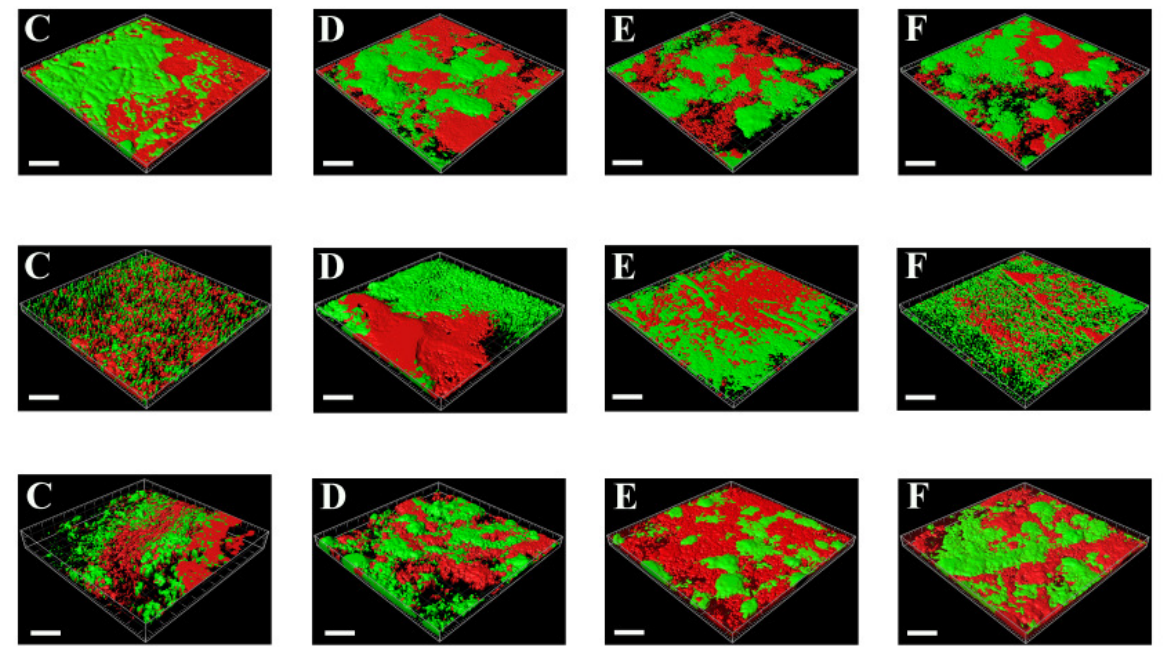
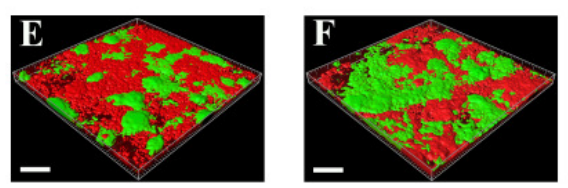

Figure 7. Live/dead staining of $S$. sanguinis, L. salivarius and oral plaque after 4 weeks of incubation at $37^{\circ} \mathrm{C}$. (A) Ti, (B) Ti_Ag, (C) Ti_N_TSP, (D) Ti_N_CM_Lf, (E) Ti_ACoI_Lf and (F) Ti_BCoI_Lf

Images of viable cells (green dots) and death bacteria (red dots) obtained by CLSM are presented in Figure 7. Treated samples reduced the number of viable bacterial while dead bacteria were detected on the modified surfaces. 


\section{DISCUSSION}

Reduction and control of dental plaque is an obvious issue in prevention and treatment of oral diseases. Various types of anti-microbial strategies have been suggested to reduce or avoid the effect of periimplantitis on surrounding tissues. The suppression of bacteria adherence, the initial step in biofilm formation, could be a prophylactic measure against the formation of the oral plaque. The application of a surface treatment or coating on titanium is another preferred strategy.

As previously mentioned, silver is a widely used biocide with effects comparable to those of antibiotics but without the development of bacteria resistance ${ }^{45,46}$. The treatment analyzed in the present study consists in the electrochemical deposition of silver ${ }^{17}$ with a low release of silver in the medium. It does not require the application of external agents, such as UV irradiation, to exert antibacterial effects.

Organofunctional alkylsilanes have been widely used to form self-assembled monolayers on hydroxyl-terminated material surfaces in order to modify the properties or chemical functions of such surfaces. Moreover, silanes are is commonly used for the immobilization of biomolecules ${ }^{20,40,47-49}$. The commonly used trialkoxysilane contain a silicon atom tetrahedrally coordinated to three similar hydrolysable groups (such as methoxy or ethoxy groups), and to a functional group that introduces the desired chemical functionality, hence reactivity, to the substrate surface. In the present project the use of two distinct organosilanes, TESPSA and CPTES, was studied. For both silanes, the silanization process is initialized by the activation of titanium surfaces by alkaline etching in order to generate hydroxyls groups onto titanium and to ensure an optimal silanization ${ }^{50}$. In previously studies has been observed a reduction in bacteria adhesion and biofilm formation when TESPSA was attached onto titanium surfaces. Therefore, no antibacterial peptide has been conjugated onto TESPSA modified surfaces due to its antibacterial effects as previously has been reported. On the contrary, CPTES was used to AMP hLf1-11 immobilization. The synthetic hLf1-11 peptide showed antibacterial activity by binding to and altering the membrane of a broad range of bacteria ${ }^{33,34,51,52}$ even when it was conjugated in titanium surfaces ${ }^{20,40}$.

ATRP methodology was developed as an alternative to hLf1-11 immobilization method. The activation of titanium was performed by plasma activation and the samples were modified either with APTES or BPTCS and followed by ATRP polymerization. ${ }^{40}$ Interestingly, these two modifications differ in the reactive group of each silane. The amino group of APTES cannot initiate ATRP, thereby an additional step is necessary to activate it. Nevertheless, BPTCS contains bromide as a terminal group which already is an initiating species. Then, radicals are generated which periodically react with the transition metal complexes in their lower oxidation state. The effectiveness of the polymer brushes is a result of the immobilized peptide and the non-fouling properties of the PDMA segment. 


\subsection{Surface characterization}

Scanning electron microscopy (SEM) was used to observe the titanium surfaces after modification (Figure 2). It seems that activation process has an important effect on morphology as thesamples etched with $\mathrm{NaOH}$ showed a stable amorphous sodium titanate layer, with a characteristic nanoporous morphology (Figure 2(B) $)^{35}$. Contrary to this, plasma activation does not show any difference in comparison with smooth titanium (Figure 2(A)). Silver electrodeposition displayed round deposits which consist of silver ${ }^{17}$ and the rounded etching was a consequence of pre-treatment which aimed at removing surface contamination and the native surface titanium oxide layer ${ }^{53}$.

The modifications observed in morphology are consistent with an increase in surface roughness in the treated samples) (Table 2). Besides, kurtosis and skewness parameters ${ }^{43}$ are influenced by the surface modification and suggested the effect in the sharpness of the peaks on the profile by silver deposition and ATRP polymerization. Noteworthy, surface roughness has an important impact in bacterial colonization because of the additional surface available for bacterial attachment ${ }^{54}$. However, in all the samples studied the average roughness values $\left(R_{a}\right)$ in the present study was below $0.2 \mu \mathrm{m}$, and based in previous studies, it is not expected to significantly increase bacteria adhesion ${ }^{55}$.

In addition to surface roughness parameters, wettability was also examined. Wettability and SFE are relevant parameters determining chemical changes in surfaces and adhesion of cells and bacteria $^{56-59}$. As shown in Table 1, the contact angles measured for treated surfaces did not show drastic difference in comparison with control surfaces, with the exception of Ti_N_TSP. We expected that CPTES silanization, due to the hydrophobic nature of silane molecules would have increase CA values. Moreover, copolymerization of DMA-co-APMA would have augmented the hydrophilic character of the samples due to the amides and amino groups introduced in the brushes. The results suggest that peptide immobilization varies the CA towards intermediate values of wettability, owing to its amphipathic character. Likewise, we believe that TESPSA silanization increased wettability values in comparison with activated titanium samples by $\mathrm{NaOH}$ treatment due to its hydrophobic character.

Some studies suggest a correlation between cellular adhesion and SFE on biomaterials ${ }^{60,61}$. They consider that values above $20-30 \mathrm{~mJ} / \mathrm{m}^{2}$ range are optimal for cell adhesion ${ }^{62}$. In this regard, we expected that wettability of treated samples would show similar cellular adhesion.

The success in coating modifications in the present study was further measured by means of XPS studies (Table 3). Silver element was deposited onto titanium surfaces when the samples were electrochemically processed. For silanization and polymerization, an increase in the C $1 \mathrm{~S}$ signal at high resolution was detected, which correlated with the presence of aliphatic carbons. This growth was accompanied with an increase in $\mathrm{N} 1 \mathrm{~s}$ for peptide immobilization due to the amide 
and amino functionalities and another chemical groups characteristic of peptides molecules ${ }^{36,37}$. The presence of silicon was another indicator of silanization and sulfur for peptide attachment.

\subsection{Biological characterization of the surfaces}

Possible cytotoxic effects of treated surfaces were studied with adhesion and proliferation assays (Figures 3 and 4). The results did not reveal reduction in viable cells for up to 7 days of incubation. According to the International Organization for Standardization (ISO 10993-6:2007), reductions in cell viability of less than $20 \%$ value is not considered cytotoxic. In addition, direct or indirect cytotoxic effects on HFFs were expected by both the hLf1-11 peptide, TESPSA and silver coatings methods used in this study, because of previous reports ${ }^{17,20,38,39}$. Once established that none of the treatments was cytotoxic, the study focused on the antimicrobial and/or antifouling properties against oral multispecies biofilm and the comparison of the effect on single species biofilm by two common oral bacteria, S.sanguinis ${ }^{63,64}$ and L.salivarius ${ }^{11}$.

In this study, the effect of five different coatings was studied on bacterial adhesion and their ability to prevent or reduce biofilm formation. The entire modified surfaces have been previously tested using single-species biofilm. Oral biofilm, however, is an aggregation of multi-species bacteria. This fact raises some doubts on the validity of extending the results of in vitro studies with single-species biofilms to in vivo situations. Peri-implantitis is associated with more complex microbiota and greater diversity than periodontitis. It is composed of gram-positive and gram-negative bacteria, and closely linked with primarily gram-negative anaerobes, including Porphyromonas gingivalis, Prevotella intermedia, Fusobacterium nucleatum and facultative Aggregatibacter actinomycetemcomitans ${ }^{65,66}$. Interestingly, previous studies have demonstrated that in vitro bacteria cultures of whole biofilms extracted from donors also reproduce the biofilm complexity found in vivo oral biofilms, with the presence of multiple gram-positive and gramnegative bacteria ${ }^{5,65}$. However, therapeutic approaches for both diseases are similar ${ }^{67}$.

Is well known that different antibacterial treatments differ in their efficacy against mono-species biofilms by different bacteria ${ }^{17,20,66}$ Therefore, development of in vitro multispecies oral plaque models are needed to achieve closer similarity with the in vivo oral and implant biofilms ${ }^{12-14}$.

The surface treated titanium samples displayed a promising reduction in bacterial adhesion (Figure 5). Overall, the results showed a reduction of biofilm on all modified surfaces, thus confirming the success of the coatings. Differences in the results between mono-species and multispecies biofilms emphasize the importance of developing further the multispecies plaque model.

Finally, the focus in the experiments was placed on the long-term antibacterial properties and biofilm formation onto modified coatings (Figure 6 and Figure 7). These experiments showed that after 4 weeks of incubation the treated surfaces still showed a reduction in bacterial viability. Differences between the three biofilm types were again evident, exhibiting the same trend as obtained in the bacterial adhesion assay. 
These results are of great interest because they demonstrate that distinct mono-species biofilms show differences in bacterial adhesion and long-term biofilm evolution. Besides, disparities are also obtained when oral plaque biofilm was used. Thus, bacterial strains exhibit different sensitivities to the activity of antibacterial and/or antifouling treatment ${ }^{66}$. Therefore, the use of mono-species biofilms should be discouraged as a model in implant-biofilm studies. In this regard, in vitro multispecies oral biofilm method seems to be a preferred alternative to a monospecies methods.

The ratio of dead/live bacteria was also evaluated (Table 4). The fact that each strain and oral plaque has a distinct response to each antibacterial coating correlates with the results obtained in bacterial viability assay. While Ti_Ag and Ti_N_TSP showed an increase in the proportion of dead cells through time, a dead/live decrease in Ti_N_CM_Lf, Ti_ACoI_Lf and Ti_BCoI_Lf was detected only after 4 weeks of incubation.

The results of the present study showed that the antibacterial and/or antifouling coatings in the present study hold a great potential for dental applications. Differences have been detected when mono-species bacteria cultures and multispecies biofilm were studied in vitro.

\section{Conclusions}

Two different in vitro biofilm models were used to study the antibacterial properties of five different titanium surface coatings. The treated surfaces were physicochemically characterized in detail and were biocompatible with human fibroblasts. Both biofilm models demonstrated a drastic reduction in bacterial adhesion and a long-term effect on biofilm formation. A higher decrease was measured when a single-species bacteria model was used, especially for $S$. sanguinis. The in vitro multi-species biofilm model is a promising strategy to study the properties of antibacterial coatings because it more realistically mimics the complex microflora of peri-implantitis.

\section{Acknowledgements}

This study was supported by the Ministry of Economy and Competitiveness (MINECO) of the Spanish Government (Projects: MAT2009-12547, MAT2012-30706), Fundación Ramón Areces and co-funded by the European Union through European Regional Development Funds.

Research reported in this study was also with the support of the Canada Foundation for Innovation (CFI fund; Project No. 32623), and the National Natural Science Foundation of China (NSFC; Grant No. 81300904).

\section{Author Contributions}

The manuscript was written through contributions of all authors. All authors have given approval to the final version of the manuscript. 


\section{References}

(1) Algraffee, H.; Borumandi, F.; Cascarini, L. Br. J. Oral Maxillofac. Surg. 2012, 50, 689-694.

(2) Klinge, B.; Hultin, M.; Berglundh, T. Dent. Clin. North Am. 2005, 49, 661-676, vii - viii.

(3) Foster, J. S.; Kolenbrander, P. E. Appl. Environ. Microbiol. 2004, 70, 4340-4348.

(4) Kolenbrander, P. E.; Andersen, R. N.; Blehert, D. S.; Egland, P. G.; Foster, J. S.; Palmer, R. J., Jr. Microbiol. Mol. Biol. Rev. MMBR 2002, 66, 486-505.

(5) Sánchez, M. C.; Llama-Palacios, A.; Fernández, E.; Figuero, E.; Marín, M. J.; León, R.; Blanc, V.; Herrera, D.; Sanz, M. Dent. Mater. 2014, 30, 1161-1171.

(6) Benítez-Páez, A.; Belda-Ferre, P.; Simón-Soro, A.; Mira, A. BMC Genomics 2014, 15, 311-324.

(7) Bjarnsholt, T. APMIS. Suppl. 2013, 1-51.

(8) Blanc, V.; Isabal, S.; Sánchez, M. C.; Llama-Palacios, A.; Herrera, D.; Sanz, M.; León, R. J. Periodontal Res. 2014, 49, 323-332.

(9) Takahashi, N. Int. Congr. Ser. 2005, 1284, 103-112.

(10) Grössner-Schreiber, B.; Teichmann, J.; Hannig, M.; Dörfer, C.; Wenderoth, D. F.; Ott, S. J. Clin. Oral Implants Res. 2009, 20, 817-826.

(11) Pham, L. C.; van Spanning, R. J. M.; Röling, W. F. M.; Prosperi, A. C.; Terefework, Z.; Ten Cate, J. M.; Crielaard, W.; Zaura, E. Arch. Oral Biol. 2009, 54, 132-137.

(12) Shen, Y.; Stojicic, S.; Haapasalo, M. J. Endod. 2011, 37, 657-661.

(13) Shen, Y.; Stojicic, S.; Haapasalo, M. J. Endod. 2010, 36, 1820-1823.

(14) Shen, Y.; Qian, W.; Chung, C.; Olsen, I.; Haapasalo, M. J. Endod. 2009, 35, 981-985.

(15) Atiyeh, B. S.; Costagliola, M.; Hayek, S. N.; Dibo, S. A. Burns J. Int. Soc. Burn Inj. 2007, 33, 139-148.

(16) DeVasConCellos, P.; Bose, S.; Beyenal, H.; Bandyopadhyay, A.; Zirkle, L. G. Mater. Sci. Eng. C 2012, 32, 1112-1120.

(17) Godoy-Gallardo, M.; Rodríguez-Hernández, A. G.; Delgado, L. M.; Manero, J. M.; Javier Gil, F.; Rodríguez, D. Clin. Oral Implants Res. 2014, n/a - n/a.

(18) Brook, L. A.; Evans, P.; Foster, H. A.; Pemble, M. E.; Steele, A.; Sheel, D. W.; Yates, H. M. J. Photochem. Photobiol. Chem. 2007, 187, 53-63.

(19) Chen, W.; Liu, Y.; Courtney, H. S.; Bettenga, M.; Agrawal, C. M.; Bumgardner, J. D.; Ong, J. L. Biomaterials 2006, 27, 5512-5517.

(20) Godoy-Gallardo, M.; Mas-Moruno, C.; Fernández-Calderón, M. C.; Pérez-Giraldo, C.; Manero, J. M.; Albericio, F.; Gil, F. J.; Rodríguez, D. Acta Biomater. 2014, 10, 3522-3534.

(21) Chen, X.; Sevilla, P.; Aparicio, C. Colloids Surf. B Biointerfaces 2013, 107, 189-197.

(22) Li, X.; Li, P.; Saravanan, R.; Basu, A.; Mishra, B.; Lim, S. H.; Su, X.; Tambyah, P. A.; Leong, S. S. J. Acta Biomater. 2014, 10, 258-266.

(23) Xie, Y.; Hill, C. A. S.; Xiao, Z.; Militz, H.; Mai, C. Compos. Part Appl. Sci. Manuf. 2010, 41, 806-819.

(24) Bauer, S.; Schmuki, P.; von der Mark, K.; Park, J. Prog. Mater. Sci. 2013, 58, 261-326.

(25) Ahmed, W.; Subramani, K. Emerging Nanotechnologies in Dentistry: Materials, Processes, and Applications; William Andrew, 2012.

(26) Costa, F.; Carvalho, I. F.; Montelaro, R. C.; Gomes, P.; Martins, M. C. L. Acta Biomater. 2011, 7, 1431-1440.

(27) Onaizi, S. A.; Leong, S. S. J. Biotechnol. Adv. 2011, 29, 67-74. 
(28) Holmberg, K. V.; Abdolhosseini, M.; Li, Y.; Chen, X.; Gorr, S.-U.; Aparicio, C. Acta Biomater. 2013, 9, 8224-8231.

(29) Chen, R.; Willcox, M. D. P.; Cole, N.; Ho, K. K. K.; Rasul, R.; Denman, J. A.; Kumar, N. Acta Biomater. 2012, 8, 4371-4379.

(30) Pasupuleti, M.; Schmidtchen, A.; Malmsten, M. Crit. Rev. Biotechnol. 2012, 32, 143-171.

(31) Reddy, K. V. R.; Yedery, R. D.; Aranha, C. Int. J. Antimicrob. Agents 2004, 24, 536-547.

(32) Bouchet, A. M.; Iannucci, N. B.; Pastrian, M. B.; Cascone, O.; Santos, N. C.; Disalvo, E. A.; Hollmann, A. Colloids Surf. B Biointerfaces 2014, 114, 363-371.

(33) Jenssen, H.; Hancock, R. E. W. Biochimie 2009, 91, 19-29.

(34) Kirkpatrick, C. H.; Green, I.; Rich, R. R.; Schade, A. L. J. Infect. Dis. 1971, 124, 539-544.

(35) Kim, H. M.; Miyaji, F.; Kokubo, T.; Nakamura, T. J. Mater. Sci. Mater. Med. 1997, 8, 341-347.

(36) Xiao, S. J.; Textor, M.; Spencer, N. D.; Wieland, M.; Keller, B.; Sigrist, H. J. Mater. Sci. Mater. Med. 1997, 8, 867-872.

(37) Xiao, S.-J.; Textor, M.; Spencer, N. D.; Sigrist, H. Langmuir 1998, 14, 5507-5516.

(38) Gao, G.; Yu, K.; Kindrachuk, J.; Brooks, D. E.; Hancock, R. E. W.; Kizhakkedathu, J. N. Biomacromolecules 2011, 12, 3715-3727.

(39) Gao, G.; Lange, D.; Hilpert, K.; Kindrachuk, J.; Zou, Y.; Cheng, J. T. J.; Kazemzadeh-Narbat, M.; Yu, K.; Wang, R.; Straus, S. K.; Brooks, D. E.; Chew, B. H.; Hancock, R. E. W.; Kizhakkedathu, J. N. Biomaterials 2011, 32, 3899-3909.

(40) Godoy-Gallardo, M.; Mas-Moruno, C.; Yu, K.; Manero, J. M.; Gil, F. J.; Kizhakkedathu, J. N.; Rodriguez, D. Biomacromolecules 2014, 16, 483-496.

(41) Matyjaszewski, K.; Miller, P. J.; Shukla, N.; Immaraporn, B.; Gelman, A.; Luokala, B. B.; Siclovan, T. M.; Kickelbick, G.; Vallant, T.; Hoffmann, H.; Pakula, T. Macromolecules 1999, 32, 8716-8724.

(42) Peltonen, J.; Järn, M.; Areva, S.; Linden, M.; Rosenholm, J. B. Langmuir 2004, 20, 9428-9431.

(43) Gadelmawla, E. S.; Koura, M. M.; Maksoud, T. M. A.; Elewa, I. M.; Soliman, H. H. J. Mater. Process. Technol. 2002, 123, 133-145.

(44) Aparicio, C.; Padrós, A.; Gil, F.-J. J. Mech. Behav. Biomed. Mater. 2011, 4, 1672-1682.

(45) Zhao, L.; Chu, P. K.; Zhang, Y.; Wu, Z. J. Biomed. Mater. Res. B Appl. Biomater. 2009, 91B, 470-480.

(46) Kim, J.; Pitts, B.; Stewart, P. S.; Camper, A.; Yoon, J. Antimicrob. Agents Chemother. 2008, 52, 1446-1453.

(47) Shriver-Lake, L. C.; Donner, B.; Edelstein, R.; Breslin, K.; Bhatia, S. K.; Ligler, F. S. Biosens. Bioelectron. 1997, 12, 1101-1106.

(48) Chen, W.-C.; Ko, C.-L. Mater. Sci. Eng. C 2013, 33, 2713-2722.

(49) Guha Thakurta, S.; Subramanian, A. Colloids Surf. Physicochem. Eng. Asp. 2012, 414, 384-392.

(50) Han, Y.; Mayer, D.; Offenhäusser, A.; Ingebrandt, S. Thin Solid Films 2006, 510, 175-180.

(51) Bellamy, W.; Takase, M.; Wakabayashi, H.; Kawase, K.; Tomita, M. J. Appl. Bacteriol. 1992, 73, 472-479.

(52) Brouwer, C. P. J. M.; Rahman, M.; Welling, M. M. Peptides 2011, 32, 1953-1963.

(53) Vermesse, E.; Mabru, C.; Arurault, L. Appl. Surf. Sci.

(54) Rodríguez-Hernández, A.; Espinar, E.; Llamas, J. M.; Barrera, J. M.; Gil, F. J. Mater. Lett. 2013, 92, 42-44. 
(55) Barbour, M. E.; O’Sullivan, D. J.; Jenkinson, H. F.; Jagger, D. C. J. Mater. Sci. Mater. Med. 2007, $18,1439-1447$.

(56) Rupp, F.; Gittens, R. A.; Scheideler, L.; Marmur, A.; Boyan, B. D.; Schwartz, Z.; Geis-Gerstorfer, J. Acta Biomater. 2014.

(57) Tzoneva, R.; Faucheux, N.; Groth, T. Biochim. Biophys. Acta BBA - Gen. Subj. 2007, 1770, 15381547.

(58) Amoroso, P. F.; Pier-Francesco, A.; Adams, R. J.; Waters, M. G. J.; Williams, D. W. Clin. Oral Implants Res. 2006, 17, 633-637.

(59) Dexter, S. C. J. Colloid Interface Sci. 1979, 70, 346-354.

(60) Harnett, E. M.; Alderman, J.; Wood, T. Colloids Surf. B Biointerfaces 2007, 55, 90-97.

(61) Bacakova, L.; Filova, E.; Parizek, M.; Ruml, T.; Svorcik, V. Biotechnol. Adv. 2011, 29, 739-767.

(62) Pegueroles, M.; Gil, F. J.; Planell, J. A.; Aparicio, C. Surf. Amp Coat. Technol. 2008, 202, 34703479.

(63) Kolenbrander, P. E.; Andersen, R. N.; Moore, L. V. Appl. Environ. Microbiol. 1990, 56, 38903894.

(64) Rickard, A. H.; McBain, A. J.; Ledder, R. G.; Handley, P. S.; Gilbert, P. FEMS Microbiol. Lett. 2003, 220, 133-140.

(65) Charalampakis, G.; Rabe, P.; Leonhardt, A.; Dahlén, G. J. Clin. Periodontol. 2011, 38, 864-871.

(66) Goudouri, O.-M.; Kontonasaki, E.; Lohbauer, U.; Boccaccini, A. R. Acta Biomater. 2014, 10, 3795-3810.

(67) D’Ercole, S.; Piattelli, A.; Marzo, G.; Scarano, A.; Tripodi, D. J. Dent. Sci. 2013, 8, 109-114. 


\section{Corresponding Author}

*Daniel Rodriguez Rius; ETSEIB-UPC - Department of Materials Science and Metallurgical Engineering; Av. Diagonal 647, 08028 - Barcelona, Spain; Phone: +34 934010711; Fax: +34 934016706; daniel.rodriguez.rius@upc.edu

\section{Table of Contents Graphic}

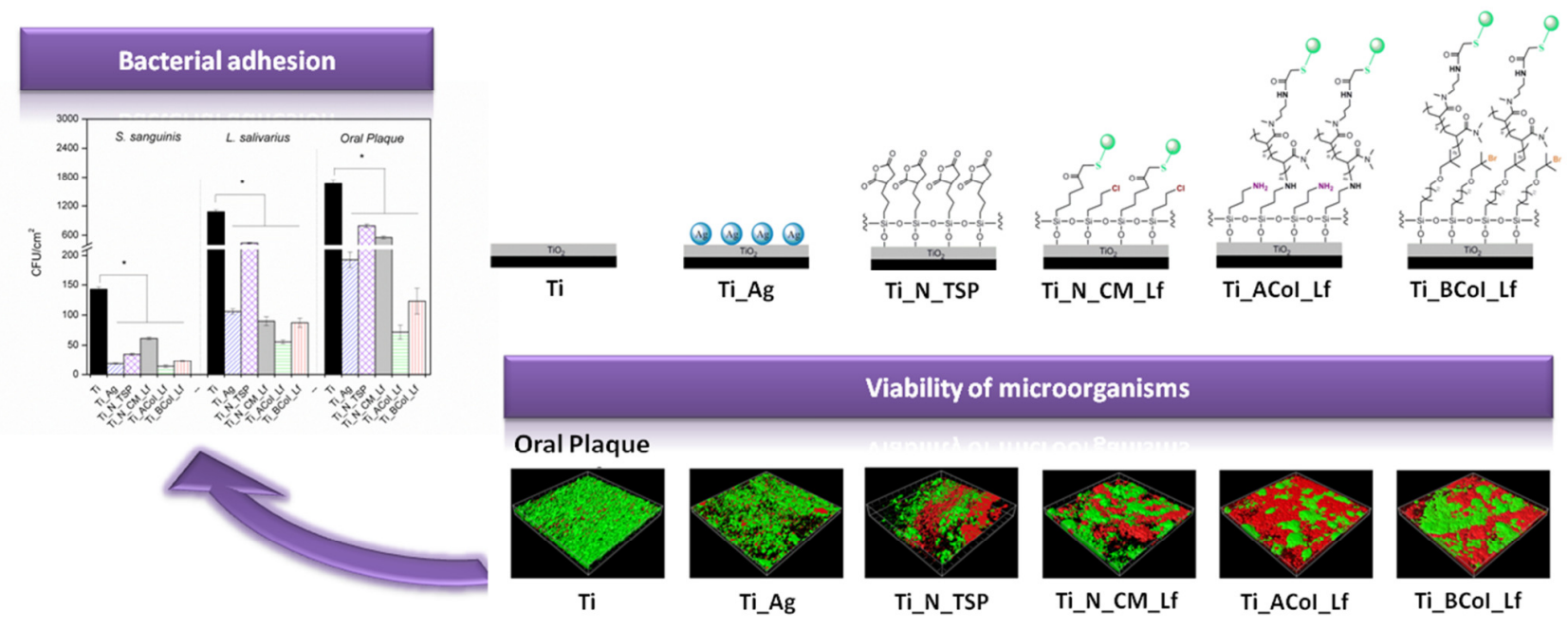

